\title{
Effect of Different Nanothymoquinone Concentrations on the Chemically-Induced Epithelial Dysplasia in the Hamster Buccal Pouch
}

\author{
Randa H. El-Sherbiny ${ }^{*}$, Magda M. Hassan, Ahmed M. Korraah \\ Department of Oral Pathology, Faculty of Dentistry, Suez Canal University, Egypt
}

\begin{abstract}
Background: Thymoquinone (TQ), an active component of Nigella sativa, has been shown to reduce tumor growth in oral cancer models. However, toxicity at high doses with poor water solubility limits its usage as a therapeutic agent. Nanoformulations were introduced to overcome these problems. Aim: The present study was designed to evaluate the effect of different nanothymoquinone (NTQ) concentrations on the chemically-induced epithelial dysplasia of the hamster buccal pouch. Materials and Methods: NTQ was prepared to improve the effectiveness of TQ. Transmission electron microscopy confirmed the particle diameter between 6 to $15 \mathrm{~nm}$. Clinical observations, histopathological alterations and complete blood count were used to investigate the effect of TQ and NTQ on severe oral epithelial dysplasia induced on hamsters' buccal pouches by 7,12-dimethylbenz[a]anthracene (DMBA). Animals received DMBA, three times weekly for six weeks then were treated with intraperitoneal injection of TQ $(0.1 \mathrm{mg} / \mathrm{kg})$ or different concentrations of NTQ $(0.1,0.05,0.025$ and $0.01 \mathrm{mg} / \mathrm{kg})$ three times per week for another 6 weeks. Results: TQ and higher concentrations of NTQ had higher anti-tumor activity towards the severe epithelial dysplasia. The best result was with NTQ $0.1 \mathrm{mg} / \mathrm{kg}$ concentration. Conclusion: NTQ is a promising candidate in cancer chemoprevention and chemotherapy as well as striated muscle regeneration.
\end{abstract}

Keywords: oral cancer, DMBA, thymoquinone nanoparticles

\section{Introduction}

Oral cancer constitutes a major health problem particularly in developing countries $^{(1)}$. It is the eighth most common cancer worldwide with high morbidity and mortality ${ }^{(2)}$. Although the incidence has decreased over the last decade, outcomes remain stagnant with only a $5 \%$ improvement in overall survival in the last 20 years ${ }^{(3)}$. Oral squamous cell carcinoma (OSCC) represents $90 \%$ of oral cancer, in its initial phase cells may progress from hyperplasia to mild dysplasia then to moderate dysplasia and later to severe dysplasia; the last phase would be OSCC(4). Every year in Egypt approximately 4.500 people will be diagnosed with OC. About half of them will die of the disease. In a study of OC in Egypt, the distribution of cases according to sites was: tongue lesions in $34.6 \%$, carcinoma of the gingival and alveolar mucosa $25 \%$ and carcinoma of lips $17.3 \%$. Less frequently affected sites were buccal mucosa $11.9 \%$, loor of the mouth $6.4 \%$ and the palate $4.7 \%(5)$ Chemoprevention in $\mathrm{OC}$ has been directed 
toward reversing premalignant lesions by interfering with the carcinogenic process early in the pathway before malignant transformation and preventing second primary tumors (SPT) ${ }^{(6)}$. To find out new therapies for cancer treatment, scientists are working with traditional or folk medicines in parallel with modern medicine. Nigella sativa $L$. has been used for medicinal purposes for centuries. Thymoquinone (TQ) is the bioactive phytochemical constituent of the seed's volatile oil of Nigella sativa. It has been shown to possess beneficial therapeutic potential on human health. Its antioxidant/anti-inflammatory effect has been reported in various disease models, including encephalomyelitis ${ }^{(7)}$, diabetes ${ }^{(8)}$, asth$\mathrm{ma}^{(9)}$ and carcinogenesis ${ }^{(3)}$. Moreover, TQ could act as a free radical and superoxide radical scavenger, as well as preserving the activity of various anti-oxidant enzymes such as catalase, glutathione peroxidase and glutathione-S-transferase ${ }^{(10)}$. It has a potential chemopreventive and chemotherapeutic activity. In vitro and in vivo researches had been thoroughly investigated the anticancer effects of TQ against several cancer cell lines and animal models ${ }^{(11)}$. The ten cancer hallmarks are common to most tumors. ${ }^{(12)}$ Drugs which interfere with one or more of these hallmarks are considered promising anticancer therapeutics. TQ holds great promise for clinical translation, considering that it affects all of cancer hallmarks except 'avoiding the immune system'. Moreover, organs like the kidneys, liver, and heart are unaffected or even protected by TQ administration which modulates their antioxidant state as well as their metabolism, thus providing strong support for its further clinical development as a safe chemotherapeutic agent $^{(13)}$. Although, TQ has tremendous potential as an anticancer therapeutic compound but its effectiveness and oral bioavailability is limited by its poor solubility. Therefore, to achieve maximum response of TQ, novel strategies are required to enhance its bioavailability and reduce toxicity ${ }^{(14)}$. Nanotechnology has been utilized for the efficient delivery of these nutraceuticals with an aim to enhance their biological activity. Nanoparticles can increase solubility and stability of phytochemicals, enhance their absorption, protect them from premature degradation in the body and prolong their circulation time. Moreover, these nanoparticles exhibit high differential uptake efficiency in the target cells over normal cells, resulting in decreased toxicity(15).

DMBA-induced hamster buccal pouch carcinogenesis is the most commonly accepted model to study the histopathological and biochemical alterations in oral carcinogenesis as well as to study the chemopreventive potential of natural products and synthetic agents. DMBA-induced oral carcinogenesis is preceded by sequential precancerous lesions such as hyperkeratosis, hyperplasia and dysplasia (6-8 weeks), which eventually turn into malignant tumors (10-14 weeks). DMBA-induced oral tumor in hamster mimics human oral tumor, morphologically, histopathologically and at the molecular level(16). TQ had been investigated as a chemotherapeutic agent on the chemically-induced epithelial dysplasia, in the hamsters' buccal pouch by DMBA, as revealed by regression of the state of dysplasia from severe to mild/moderate when given after DMBA applications ${ }^{(17)}$. In the present study, NTQ was prepared in different concentrations (0.1, $0.05,0.025$ and $0.01 \mathrm{mg} / \mathrm{kg}$ ) to study their effects on the chemically-induced epithelial dysplasia, in the hamster buccal pouch by DMBA.

\section{Material and Methods}

Chemicals: $0.5 \%$ solution of 7,12-Dimethylbenz (a) anthracene (DMBA) dissolved in heavy mineral oil (U.S.P) (Sigma-Aldrich 
Co., Saint Louis, MO, USA), TQ (Sigma Aldrich Co., Saint Louis, MO, USA) and NTQ which prepared as the following: Seven (7) mg of lecithin, $1 \mathrm{mg}$ TQ and $7 \mathrm{mg}$ TritonX100 were dissolved in $3 \mathrm{ml}$ chloroform which was evaporated under reduced pressure at room temperature using a horizontal rotary evaporator (BÜCHI), the film was re-dissolved in chloroform and the whole process of evaporation was repeated under vacuum until a very uniform and homogeneous thin film was obtained. Afterwards the film was hydrated with 10 $\mathrm{ml}$ deionised water and left for 24 hours at room temperature for complete hydration. To enhance the encapsulation efficiency of the drug, the mixture was heated at approximately $50^{\circ} \mathrm{C}$ for $20-30$ minutes with vigorous vortexing every $2-3$ minutes. The NTQ was kept in dark $\left(+4^{\circ} \mathrm{C}\right)$ till use. The nanoparticles were examined by transmission electron microscope to characterize their microstructure. Animals: Seventy-five males golden Syrian hamsters, weighing 100-120 grams and aged 7-9 weeks were used in the study. They were obtained from Theodor Bilharz Research Institute (TBRI), Cairo, Egypt. Experiment was performed at the Animal House, Faculty of Pharmacy, Suez Canal University, Ismailia, Egypt. The animals were housed, five per cage and were given pellets made up of seeds, grains and cracked corn that were purchased from TBRI, and tap water, ad libitum. The animals were kept in a controlled environment under standard conditions of temperature and humidity with an alternating light/dark cycles with 12 hoursintervals.

Experimental setup: The hamsters were divided into four groups. Group A; 15 animals were served as control. The Group B (10 animals), C (10 animals) and D (40 animals) were painted with $0.5 \%$ DMBA three times per week for 6 weeks on the left buccal pouches, using No. 4 hair camel brush, to induce the oral epithelial dysplasia. After that, for another 6 weeks, animals in group $B$ were received no other treatment, animals in group $C$ were intraperitoneally injected with TQ $(0.1 \mathrm{mg} / \mathrm{kg})$ three times weekly while animals in group $D$ were subdivided to subgroups D1, 2, 3 and 4 and each subgroup were intraperitoneally injected with definite concentration of NTQ $(0.1,0.05,0.025$ and $0.01 \mathrm{mg} / \mathrm{kg}$ respectively) three times per week. Animals were sacrificed by inhalation of a lethal dose of diethyl ether. Hematological investigation: Blood samples were withdrawn for CBC in each case. Histopathological examination: pouches were surgically excised, fixed in $10 \%$ neutral formalin solution, embedded in soft paraffin wax, sectioned serially into $5 \mu \mathrm{m}$, and routinely stained with H\&E. Due to the thin nature of the hamster buccal pouch epithelium; dysplasia grading was graded as follow ${ }^{(18)}$ : i) Mild dysplasia: when less than three features were seen. ii) Moderate dysplasia: when three to seven features were seen. iii) Severe dysplasia: when seven or more features were seen. iv) Carcinoma in situ: when dysplastic changes were seen from top to bottom with intact basement membrane. Photomicrographs were taken, using Soft Imaging Analysis System (BX50F4, Olympus Optical Co., Japan).

\section{Statistical analysis}

Data from blood samples were statistically analyzed using one way analysis of variance (ANOVA) according to Steel and Torrie (1984). Software program, CoStat version 6.311 was used to perform the analysis and means were compared using LSD $(P \leq 0.05$. were considered statistically significant).

\section{Results}

Size and shape of NTQ particles (figures 1 and 2): The images of TEM showed the monodispersity (small range of particles size ranging from 6-15nm) of the prepared 
NTQ. Nanoparticles appear as dark circular particles (spherical in shape) whereas; the liposomes appear as faint cycles surrounding the particles. The prepared translucent emulsion was stable for six weeks as no precipitation was observed.

Clinical findings: (table 1 \& figures 3-5) demonstrates the clinical findings ap- peared on the hamsters during the experiments where animals painted with DMBA for 6 weeks showed hair loss, red macules or papules and shorting in the left pouches $(1-2 \mathrm{~cm})$ compared to the control pouches $(5 \mathrm{~cm})$ and at the $12^{\text {th }}$ week, exophytic masses were found in groups B and D4. In group D1, marked increase in the length of the left pouches again $(\sim 3-4 \mathrm{~cm})$.

Table 1: Gross findings recorded on hamsters during the experiment

\begin{tabular}{|c|c|c|c|c|}
\hline Gross findings & 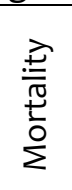 & 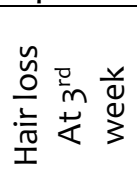 & 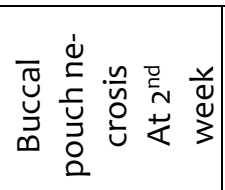 & 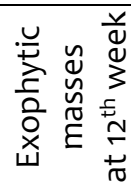 \\
\hline Group A (15 animals untreated) & No & No & No & No \\
\hline $\begin{array}{l}\text { Group B (10 animals DMBA alone for } 6 \text { wks } \\
\text { and left without treatment for another } 6 \\
\text { weeks) }\end{array}$ & No & $100 \%$ & $100 \%$ & $100 \%$ \\
\hline $\begin{array}{l}\text { Group C (10 animals DMBA } 6 \text { weeks then } \\
\text { whole TQ molecule }(0.1 \mathrm{mg} / \mathrm{kg}) \text { for another } 6 \\
\text { weeks) }\end{array}$ & No & $100 \%$ & $100 \%$ & No \\
\hline $\begin{array}{l}\text { Group D1 (10 animals DMBA } 6 \text { weeks then } \\
\text { NTQ (0.1 mg/kg) for another } 6 \text { weeks) }\end{array}$ & No & $100 \%$ & $100 \%$ & No \\
\hline $\begin{array}{l}\text { Group D2 (10 animals DMBA } 6 \text { weeks then } \\
\text { NTQ }(0.05 \mathrm{mg} / \mathrm{kg}) \text { for another } 6 \text { weeks })\end{array}$ & No & $100 \%$ & $100 \%$ & No \\
\hline $\begin{array}{l}\text { Group D3 (10 animals DMBA } 6 \text { weeks then } \\
\text { NTQ }(0.025 \mathrm{mg} / \mathrm{kg}) \text { for another } 6 \text { weeks })\end{array}$ & No & $100 \%$ & $100 \%$ & No \\
\hline $\begin{array}{l}\text { Group D4 (10 animals DMBA } 6 \text { weeks then } \\
\text { NTQ }(0.01 \mathrm{mg} / \mathrm{kg}) \text { for another } 6 \text { weeks) }\end{array}$ & No & $100 \%$ & $100 \%$ & $40 \%$ \\
\hline
\end{tabular}

Results of blood analysis (table 2): Statistical analysis of total WBCs count, in comparison to untreated group $(A)$, showed no significant difference with groups $C$ and D1, while increased with the other groups. Lymphocytes percentage, show-ed no significant difference with groups $D_{3}$ and D4, while significantly different with groups B2, C, D1 and D2 as it increased with groups C, D1 and D2 and decreased with group B2. Total neutrophils in test groups showed no significant different with group D1, while increased with the other groups. Total RBCs count showed no significant difference with group D1 and decreased with the other groups. Hb level showed no significant difference in groups D1 and D2, while it was decreased in the other groups. Platelets count showed no significant difference in groups $C$ and $D 1$, while increased was with groups B2, D2, D3 and D4. Histopathologic results (table 3 and figures 6-12): Group $B$ showed focal papillomatous overgrowths represented well differentiated squamous cell carcinoma; in the form of invasive islands to the connective tissue, showing dysplastic squamous cells and keratin pearls and the rest of the pouches showed focal areas of epithelial hyperplasia and hyperkeratinization with severe dysplastic changes. The underlying connective tissue was collageneous, with severe chronic inflammatory cellular infiltrate and dilated blood vessels. Group $C$ 
showed mild to moderate dysplastic changes. Group D1 showed focal epithelial hyperplasia, hyperkeratinization to mild dysplastic changes. Loss of polarity and hyperplasia of basal cell layer with nuclear hyperchromatism. The underlying connective tissue showed mild chronic inflammatory cellular infiltrate and increase in density of muscular layer. Group D2 showed focal ar eas of mild to moderate dysplastic changes. Group D3 showed focal areas of moderate to severe dysplastic changes. Group D4 showed focal papillomatous overgrowths represented well differentiated squamous cell carcinoma and the rest of the pouches showed focal areas of epithelial hyperplasia and hyperkeratinization with severe dysplastic changes.

Table 2: Statistical analysis of selected CBC findings

\begin{tabular}{|l|c|c|c|c|c|c|}
\hline Treat. & WBCs & Lymph. & Neu. & RBC & Hb & Plt \\
\hline Negative. control. (A) & $5.4 \pm 0.1^{\mathrm{bc}}$ & $82.3 \pm 1.4^{\mathrm{b}}$ & $4.5 \pm 0.8^{\mathrm{d}}$ & $8.7 \pm 0.1^{\mathrm{a}}$ & $13.7 \pm 0.3^{\mathrm{a}}$ & $321 \pm 42^{\mathrm{b}}$ \\
\hline Positive. control. (B) & $3.9 \pm 0.6^{\mathrm{c}}$ & $73.7 \pm 1.9^{\mathrm{c}}$ & $2.9 \pm 0.8^{\mathrm{dc}}$ & $7.5 \pm 0.9^{\mathrm{c}}$ & $12.9 \pm 1.4^{\mathrm{b}}$ & $431 \pm 13^{\mathrm{a}}$ \\
\hline TQ 0.1mg/kg(C) & $5.9 \pm 1.2^{\mathrm{bc}}$ & $90.3 \pm 4.5^{\mathrm{a}}$ & $11.5 \pm 4.8^{\mathrm{bc}}$ & $7.7 \pm 0.3^{\mathrm{bc}}$ & $13.5 \pm 0.5^{\mathrm{ab}}$ & $318 \pm 44^{\mathrm{b}}$ \\
\hline NTQ 0.1mg/kg. (D1) & $6.7 \pm 1.5^{\mathrm{bc}}$ & $93.5 \pm 1.9^{\mathrm{a}}$ & $6.4 \pm 2^{\mathrm{d}}$ & $8.4 \pm 0.4^{\mathrm{a}}$ & $13.9 \pm 0.6^{\mathrm{a}}$ & $324 \pm 50^{\mathrm{b}}$ \\
\hline NTQ 0.05mg/kg. (D2) & $7.9 \pm 2.8^{\mathrm{b}}$ & $90.6 \pm 3.1^{\mathrm{a}}$ & $7.3 \pm 2.5^{\mathrm{cd}}$ & $7.7 \pm 0.6^{\mathrm{bc}}$ & $13.7 \pm 0.4^{\mathrm{a}}$ & $369 \pm 74^{\mathrm{ab}}$ \\
\hline NTQ 0.025 mg/kg.(D3) & $7.7 \pm 2.0^{\mathrm{b}}$ & $80.3 \pm 5 \cdot 3^{\mathrm{b}}$ & $12.9 \pm 6^{\mathrm{ab}}$ & $7.8 \pm 0.4^{\mathrm{bc}}$ & $13.6 \pm 0.6^{\mathrm{ab}}$ & $413 \pm 73^{\mathrm{a}}$ \\
\hline NTQ 0.01mg/kg. (D4) & $12.3 \pm 2.3^{\mathrm{a}}$ & $79.9 \pm 13.2^{\mathrm{b}}$ & $16.6 \pm 10.1^{\mathrm{a}}$ & $7.8 \pm 0.3^{\mathrm{bc}}$ & $13.4 \pm 1^{\mathrm{ab}}$ & $405 \pm 14^{\mathrm{a}}$ \\
\hline
\end{tabular}

Note: Data are expressed as the mean \pm SD for 10 hamsters in each group. Values not sharing a common superscript letter in the same column, differ significantly at $p<0.05$. (One-way ANOVA test).

\section{Discussion}

The tumor induction protocol of Shklar $(1972)^{(19)}$ was applied to chemically-induce epithelial dysplasia in HBP, to study the effect of different NTQ concentrations as chemopreventive and chemotherapeutic agents. The development of DMBA-induced carcinogenesis in a hamster model is parallel to the development of oral cancer in human, i.e. progression from normal stratified squamous epithelium to hyperplasia and hyperkeratosis, followed by dysplasia, that progresses in situ and invasive carcinomas $^{(20,21)}$. NTQ was prepared with liposome carriers to enhance solubility, decrease toxicity and investigate their ability to inhibit malignant transformation of hamster buccal pouch. Lecithin is well characterized and safe lipid that is commonly used in liposomes preparation and it was used in this study as structural unit of the liposome design. NTQ is a small non-polar molecule, so it accumulates in liposomes and increases the hardness of the liposomes membrane which may decrease their uptake by the cell. Triton $\mathrm{x}-100$ was added to give more flexibility to liposome membrane. The addition of triton $\mathrm{x}-100$ did not provoke enhancement of drug release, suggesting that small ratio of triton $\mathrm{x}-100$ maintain the integrity of the liposomes $^{(22)}$.The resulted NTQ was spherical in shape with size range from 6-15 nm which is considered the best shape and size in cancer treatment. Previous studies showed that anticancer nanoparticles with smaller sizes exhibited enhanced performance in vivo, such as greater tissue penetration and enhanced tumor inhibition, particularly those with size around or smaller than $50 \mathrm{~nm}^{(23,24)}$ We found that spherical nanoparticles with diameters of 14 or $75 \mathrm{~nm}$ were taken up by cells $375^{-}$ $500 \%$ more compared to $74 \times 14 \mathrm{~nm}$ rodshaped particles. One potential reason for this disparity in cell uptake could be the difference in particle curvature, which affects 
Table 3: Histological changes recorded in the left buccal pouches of hamsters in control and experimental animals.

\begin{tabular}{|l|c|c|c|c|}
\hline & \multicolumn{4}{|c|}{ Histological changes } \\
\hline Groups & $\begin{array}{c}\text { Hyper-kerat- } \\
\text { inization }\end{array}$ & Hyperplasia & Dysplasia & SCC \\
\hline A: Control & No & No & No & No \\
\hline $\begin{array}{l}\text { B: }(6 \text { wks DMBA \& } 6 \\
\text { wks no treatment }\end{array}$ & Severe & Severe & Severe & $\begin{array}{c}\text { Well } \\
\text { differentiated }\end{array}$ \\
\hline C: TQ $(0.1 \mathrm{mg} / \mathrm{kg})$ & Moderate & Moderate & Mild to mod. & No \\
\hline D1: NTQ $(0.1 \mathrm{mg} / \mathrm{kg})$ & Mild & Mild & Mild & No \\
\hline D2: NTQ $(0.05 \mathrm{mg} / \mathrm{kg})$ & Moderate & Moderate & Mild to Mod. & No \\
\hline D3: NTQ $(0.025 \mathrm{mg} / \mathrm{kg})$ & Moderate & Severe & Mod. to severe & No \\
\hline D4: NTQ $(0.01 \mathrm{mg} / \mathrm{kg})$ & Severe & Severe & Severe & $\begin{array}{c}\text { Well } \\
\text { differentiated }\end{array}$ \\
\hline
\end{tabular}

SCC= Squamous cell carcinoma

the particle contact area with the cell membrane ${ }^{(25)}$. Buccal necrosis with DMBA applications may be due to either local toxic effect of DMBA or local infection that elicited a severe inflammatory response. DMBA had possessed an immunosuppressive effect on hamsters which reflected by a significant reduction of total lympho

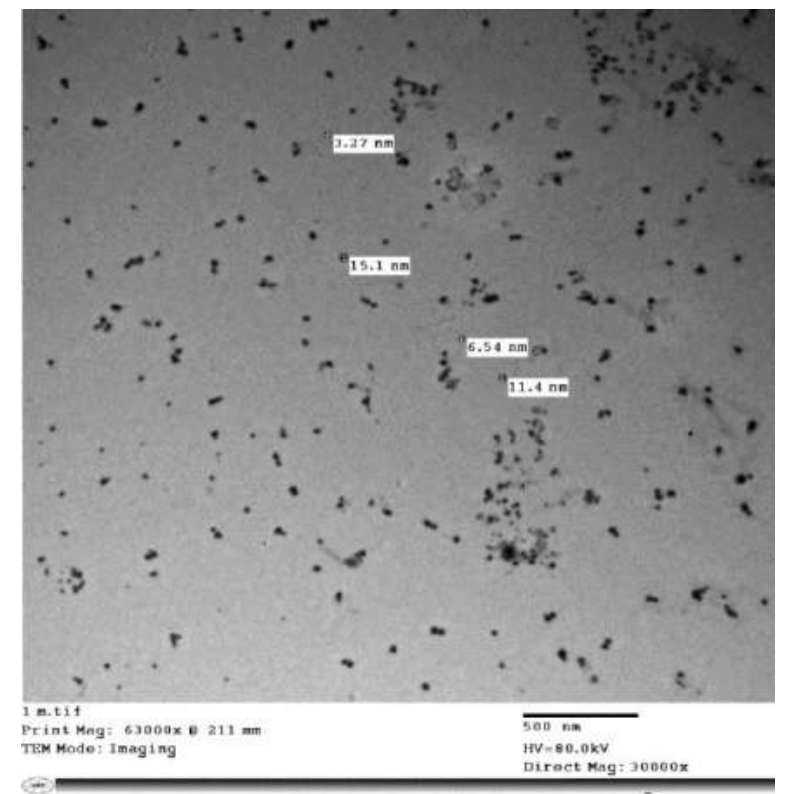

Figure 1: TEM image of the prepared NTQ. (Low power). The average diameter of NTQ ranges from 6-15 nm. cytes count in animals treated by $\mathrm{DMBA}^{(26)}$. An interesting clinical finding from the present work, was the elongation of the shortened DMBA-painted pouches $(1-2 \mathrm{~cm})$ followed by 6 weeks NTQ $(0.1 \mathrm{mg} / \mathrm{kg}$ body weight) to be about $4 \mathrm{~cm}$. This elongation was associated with regeneration of the striated muscle layer, seen histologically.

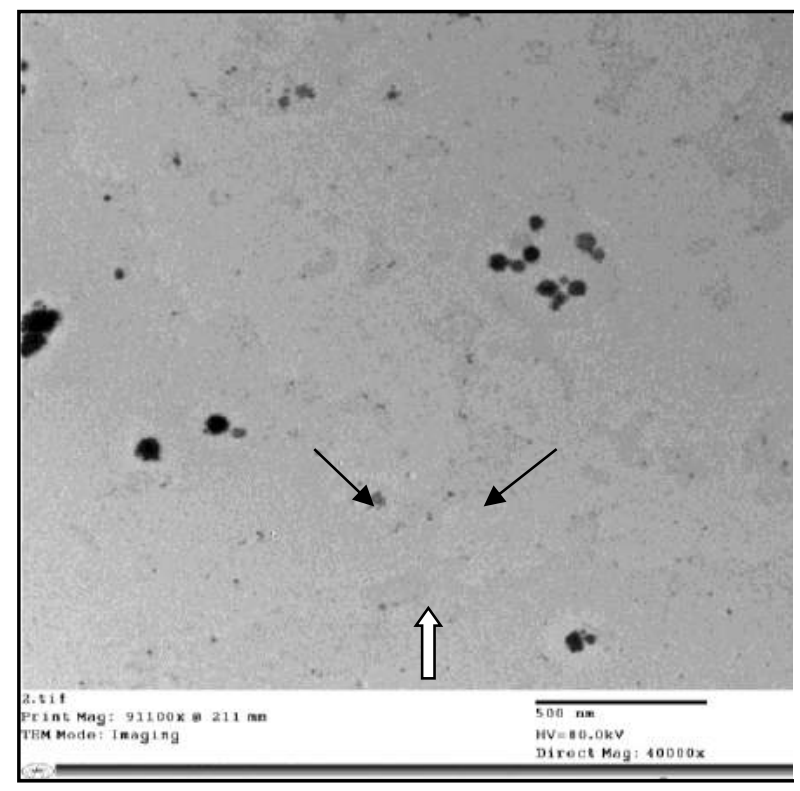

Figure 2: TEM image of the prepared NTQ. (Highpower). Nanoparticles appear as dark circular particles (spherical in shape) (black arrows) whereas; the liposomes appear as faint cycles surrounding the particles (white arrow 


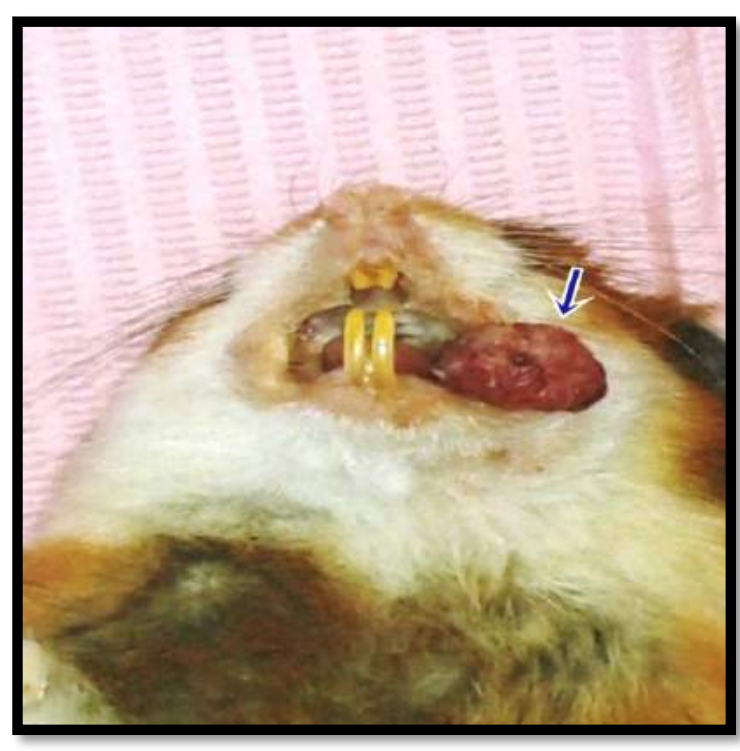

Figure 3: Exophytic mass with papillary projections on the left buccal pouch at the $12^{\text {th }}$ week in group B.

This finding strongly confirms the effect of NTQ at that specified dose on muscle regeneration. Pro-inflammatory macrophages (Ms 1) are found during the early stages after muscle damage, participate in the processing and presenting antigens and in phagocytic removal of necrotic material. They also produce high levels of proinflammatory cytokines as TNF- $\alpha$, IL-1 $\beta$, and IL-12. While $M 2$ is further divided into distinct subtypes, as $M$ 2a that are acti

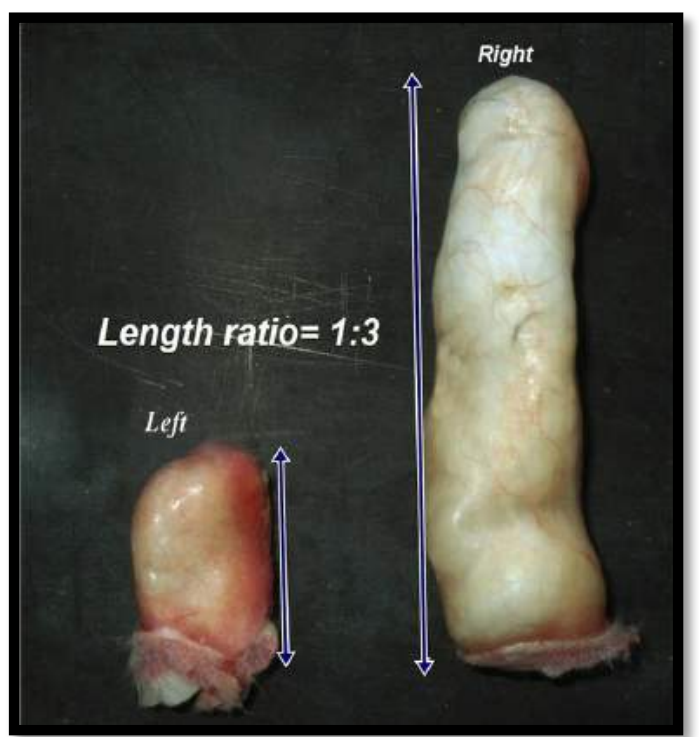

Figure 4: Marked difference in length between left and right buccal pouches of the same hamster in group $B$.

vated by Th2 cytokine IL-4 and IL-13. They are commonly associated with tissue repair, wound healing and fibrosis. While $\mathrm{M} 2 \mathrm{C}$ are primed by IL-10, and releasing antiinflammatory cytokines so considered to be anti-inflammatory. They deactivate $\mathrm{M}_{1}$ phenotype and promote proliferation of non-myeloid cells, as well. i.e. classically activated $\mathrm{M} 1$ are usually found in early stages after muscle injury, closely followed by M2c macrophages ${ }^{(27)}$.

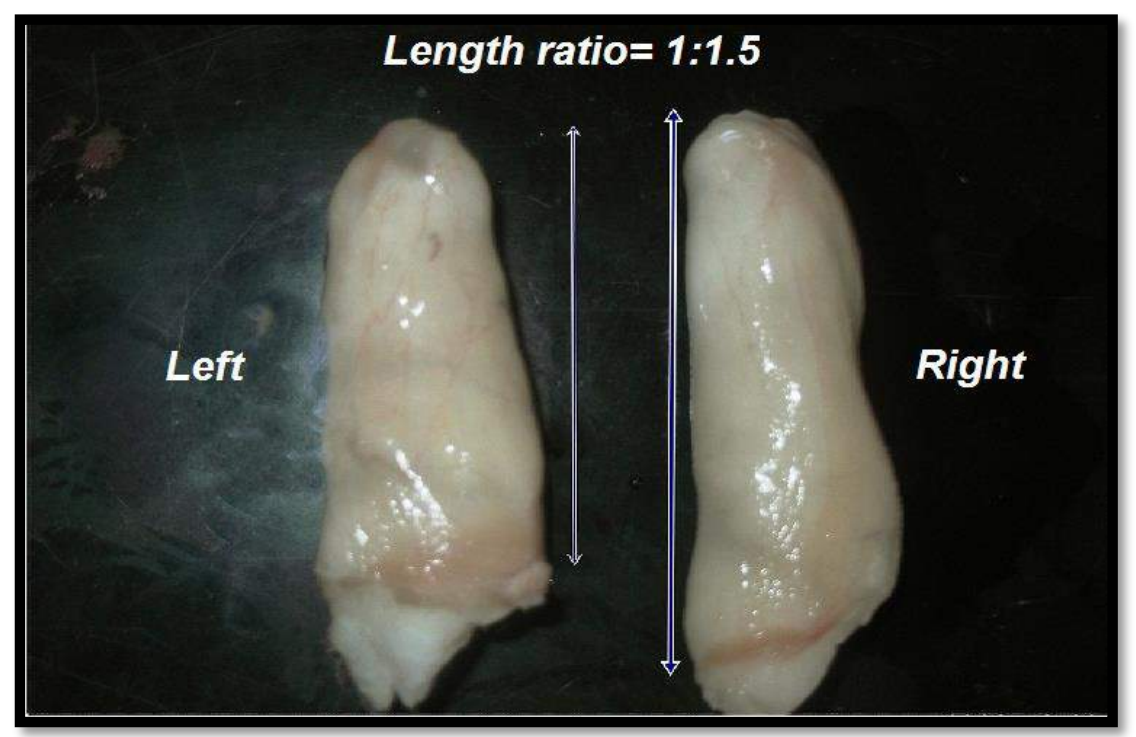

Figure 5: Left and right buccal pouches of the same hamster in group D1. It shows increase of length of left buccal pouch to near the right pouch length (unpainted pouch). 
It can then be postulated that the known anti-inflammatory effect of TQ, has a stronger effect when it is in the nano-size, in particular (0.1 $\mathrm{mg} / \mathrm{kg}$ ) revealed most probably through activating the macrophage subtype (M2) inducing activation and differentiation of the muscle stem cells. Furthermore, it appears that NTQ (0.1

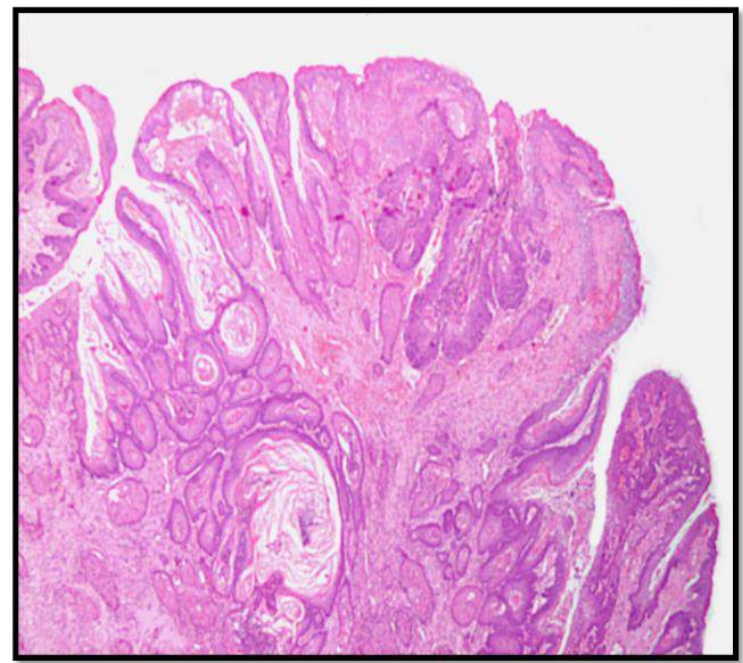

Figure 6: (Group B) H\&E stained section showed papillomatous over growth showing well and moderate differentiated squamous cell carcinoma in (x4). mg) has direct effect on fibroblasts and muscles in the painted pouches. TGF- $\beta 1$ has the potential to induce fibrosis around myofibers, and was shown to be expressed in normal muscle after injury, as well as in chronic inflammatory muscular conditions as dystrophic muscle (DMD) and $\mathrm{mdx}$ mice model $^{(28)}$.

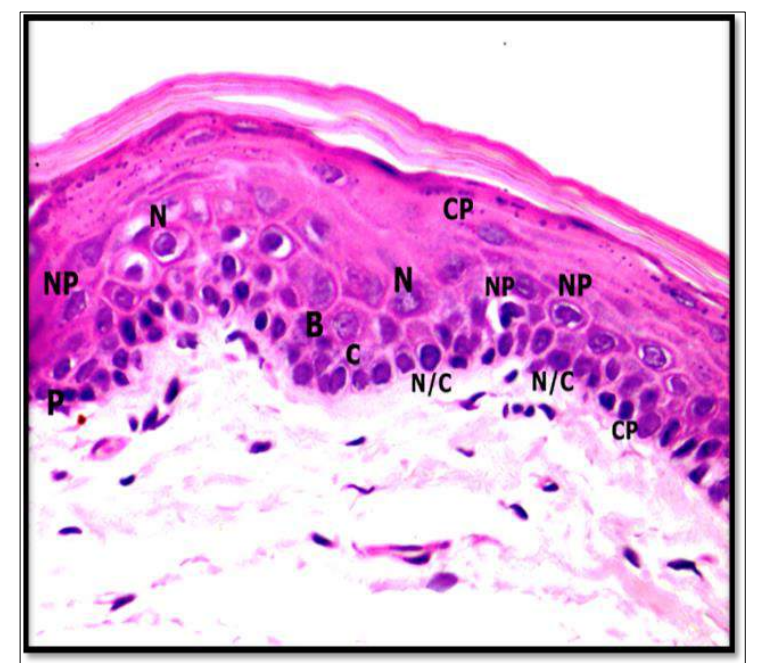

Figure 7: (Group C) H\&E stained section showed epithelial hyperplasia and hyperkeratinization with moderate dysplastic changes in. Loss of polarity (P) and hyperplasia (B) of basal cell layer, nuclear hyperchromatism (C), prominent nucleoli $(\mathrm{N})$, nuclear (NP) and cellular pleomorphism (CP) and reversed nuclear/ cytoplasmic ratio $(\mathrm{N} / \mathrm{C})$ were seen (x40).

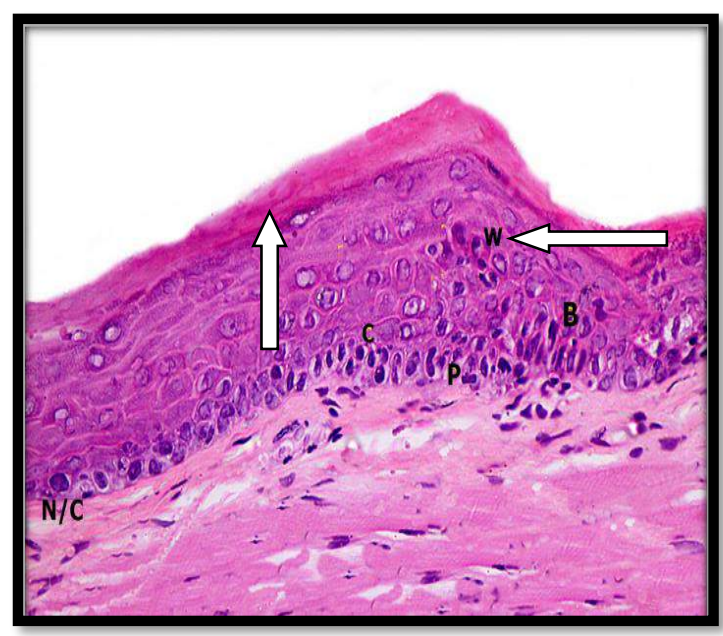

Figure 9: (Group D2) H\&E stained section showing mild to moderate dysplastic changes. Basal layer hyperplasia (B) with loss of polarity $(P)$, nuclear hyperchromatism (C), altered nuclear cytoplasmic ratio $(\mathrm{N} / \mathrm{C})$ and swirling pattern of epithelial cells (w) were seen. (x20).
Figure 8: (Group D1) H\&E stained section showing focal epithelial hyperplasia $(\mathrm{H})$, hyperkeratinization (K) and mild dysplastic changes (loss of polarity of basal cell layer $(P)$, nuclear hyperchromatism (C) and increase in density of muscular layer (arrows). (x40). 
TGF- $\beta 1$ was found to stimulate fibroblasts to produce ECM proteins (collagen, and fibronectin), as well decreasing production of enzymes that degrade the ECM as collagenase ${ }^{(29,30)}$. Another clinical finding in this study was marked hair loss. This could be due to direct toxicity to hair follicles by the carcinogen. Skin eruptions and ulcers appeared at areas of hair loss. A lot of studies reported the same results ${ }^{(31,32)}$. The exophytic papillary masses, turned to be OSCC, histologically, in animals treated with DMBA only and NTQ $0.01 \mathrm{mg} / \mathrm{kg}$ (groups B2 and D4, respectively). No exophytic papillary masses appeared with TQ $0.1 \mathrm{mg} / \mathrm{kg}$ and NTQ $0.1,0.05$ and $0.025 \mathrm{mg} / \mathrm{kg}$ concentrations It may be due to the protective effect of TQ and NTQ which delayed or regressed the effect of DMBA. Same results were recorded by previous studies with groups given TQ after DMBA application. (31). Histopathological results, of the present study, showed that the untreated control group and right pouches in all animals revealed the four distinct normal layers as first described by Salley $(1954)^{(33)}$. On the other; animals treated with DMBA for six weeks and left without treatment for another six weeks, oral squamous cell carcinoma appeared after 12 weeks. This finding was in agreement with numerous previous studies concerning carcinogenesis induction by DMBA in the $\operatorname{HBP}(33,34)$. The histological changes taking place on HBP under the influence of DMBA application were reported as four histological changes: inflammation, degeneration (necrosis), regeneration and hyperplasia. Degeneration and necrosis were the prominent features 24 hours after thrice DMBA-applications, followed by hyperplasia from the sixth to the fifteenth applications. The epithelium became thickened from normal (24) cell layers to (6-8) cell layers leading to a whitish mucosa(31). The present results fur- ther revealed that TQ and higher concentrations of NTQ had regressed severe/ invasive carcinoma (groups B1 and B2) to mild/ moderate dysplasia (groups C, D1 and D2). The therapeutic effect of TQ could be due to its effect on cancer hallmarks where TQ showed antiproliferative ${ }^{(35)}$, and anti-inflammatory effect(36), induce cell cycle arrest and apoptosis ${ }^{(37)}$, reactive oxygen species (ROS) generation( ${ }^{(38)}$, modulate tumor suppressor gene $\mathrm{p} 53^{(17)}$, inhibit vascular endothelial growth factor (VEGF) ${ }^{(39)}$, regulate cellular metabolism and inhibit invasion and metastasis through NF-kB pathway (40). From the present results, NTQ $0.1 \mathrm{mg} / \mathrm{kg}$ appeared to have a stronger anticancer effect over TQ $0.1 \mathrm{mg} / \mathrm{kg}$ while NTQ 0.05 $\mathrm{mg} / \mathrm{kg}$ have the same effect as TQ 0.1 $\mathrm{mg} / \mathrm{kg}$. Effect of NTQ $0.025 \mathrm{mg} / \mathrm{kg}$ was lower than the effect of higher concentrations, but it prevented OSCC formation in comparison to NTQ $0.01 \mathrm{mg} / \mathrm{kg}$ which appeared to have no effect against the mutagenic effect of DMBA. TQ liposomal carriers have been prepared, characterized and tested against MCF-7 and T47D breast cancer cell lines and normal periodontal ligament fibroblasts. The drug carriers were effective in inhibiting the proliferation of cancer cells and were non-toxic to normal fibroblasts (22). As WBCs are known to fight infection and disease, so when WBC counts are low, there is a higher risk of infection by viruses and bacteria. Neutrophils are a type of WBCs that surround and destroy bacteria in the body. They are very important in fighting infection as well(41). The present results indicate that DMBA is a potent immunosuppressive agent by lowering significantly WBC count, lymphocyte, neutrophils as well as RBCs and $\mathrm{Hb}$. This observation is in consistent with others who indicated that DMBA is a potent carcinogen that induces immunosuppression of both humoral and cell-mediated immun- 
ity in different animal models. They reported that DMBA has suppressed B and Tcell mitogenesis, decreased natural killer cell activity, as well as decreased neutrophils and lymphocytes levels lymphocytes levels $(42,43)$. Decreasing in RBC count and $\mathrm{Hb}$ levels represent anemia which was a common complication with inflammatory diseases including cancer. One of the important contributing factors of anemia in cancer is iron deficiency secondary to nutritional deficiencies, which were noticed as loss of appetite, difficulty to eat and store food with shortening of painted pouches with DMBA, NTQ 0.025 and NTQ 0.01 $\mathrm{mg} / \mathrm{kg}$ where the previously shortened pouches (after 6 weeks of DMBA) that had regenerated after TQ $0.1 \mathrm{mg} / \mathrm{kg}$, NTQ 0.1 and $0.05 \mathrm{mg} / \mathrm{kg}$ treatment, feeding would be much better, reflected as improvement of the general health and sign elevation of all tested blood parameters . Concomitant with the positive effect of TQ, from the present work, on RBCs and $\mathrm{Hb}$, previous study was found that treatment of rats with TQ for up to 12 weeks,

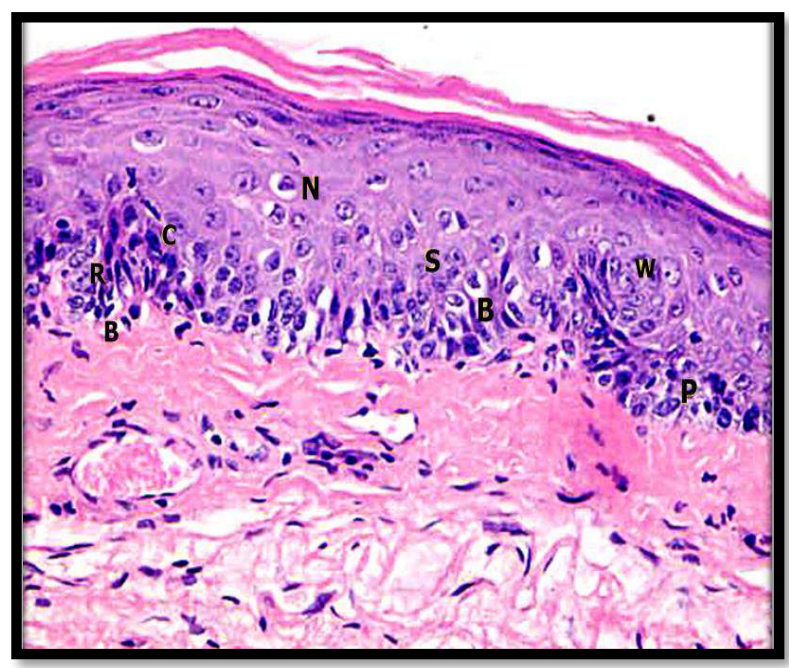

Figure 10: (Group D3) H\&E stained section showing moderate to severe dysplastic changes. Basal layer hyperplasia (B) with loss of polarity (P) nuclear hyperchromatism (C), prominent nucleoli $(\mathrm{N})$, cellular and nuclear pleomorphism, widened rete ridges $(R)$ and swirling pattern of epithelial cells $(W)$ were seen. $(x 40)$. had resulted in an increase of both the packed cell volume (PCV) and haemoglobin $^{(44)}$. Platelets were found to have an important role in carcinogenesis directly related to their normal function in promotion of vascular integrity. Circulating tumor cells may use platelets as a protective shield from the attack of immune system and as facilitators for attachment to endothelial cells at metastatic sites( ${ }^{(45)}$. Three major theories of tumor-platelet interaction were supposed: 1 . among cancer patients with increased platelet counts, platelets could increase tumor growth and angiogenesis by secreting a cocktail of predominantly proangiogenic cytokines within a potentially prothrombotic tumor microcirculation. 2. Platelets enhance tumor metastasis by protecting tumor cells from physical factors such as shear stress and the host's immune response by coating circulating tumor cells. 3. The increase in platelet counts may be an epiphenomenon of tumor growth, as tumors secret cytokines that induce thrombopoiesis(46).

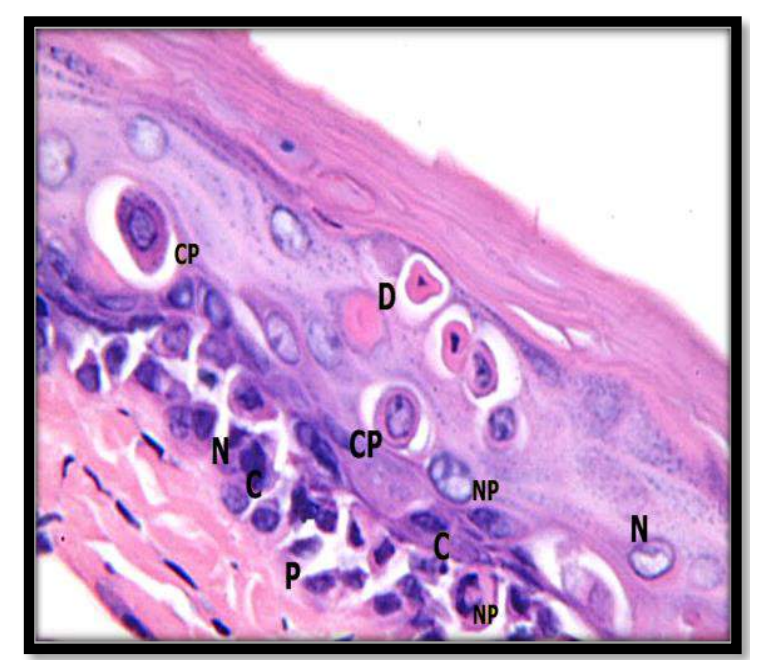

Figure 11: (Group D4) H\&E stained section showin! severe dysplastic changes. Dyskeratosis (D), cellula (CP) and nuclear (NP) pleomorphism, hyperchrome tism (C), loss of polarity (P) of basal cell layer, $r \epsilon$ versed nuclear/cytoplasmic ratio (CP) and prom nent nucleoli $(N)$ were seen. (x100). 


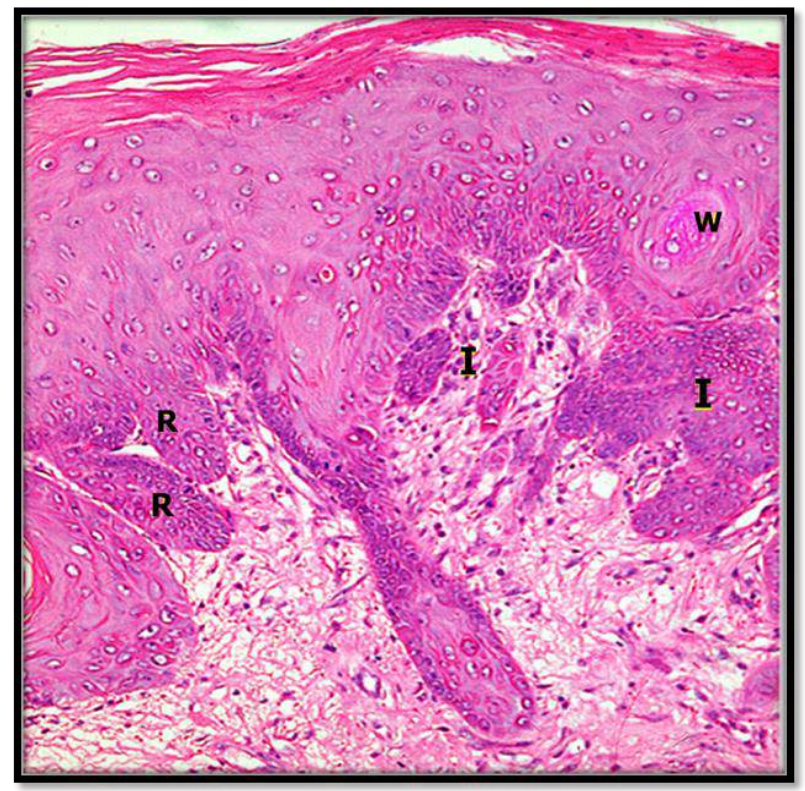

Figure 12: (Group D4) H\&E stained section showing superficial invasion, invading islands ( $I$ ) to the underlying connective tissue, swirling of epithelial cells (W) and prominent rete ridges $(\mathrm{R})$ are evident. (x40).

The present study may prove that higher NTQ concentrations are more effective than free TQ, in treatment of severe dysplasia or squamous cell carcinoma. These findings will lead to a decrease in the dose of TQ formulations, in consequence decreasing in their side effects that is to say, NTQ preparations are believed to hold greater promise than free TQ for two main reasons: (1) their enhanced activity due to better targeting of the cancer hallmarks and (2) their improved bioavailability and distribution.

\section{Conclusions}

We conclude that: 1 . The beneficial therapeutic effect of NTQ against the strong cytotoxic and carcinogenic action of DMBA. 2. A safe natural agent for efficient striated muscle regeneration that hopefully is as much effective for human's application. 3 . NTQ $(0.1 \mathrm{mg} / \mathrm{kg})$ appears to have a better effect against epithelial dysplasia in comparison to TQ and other concentrations of NTQ (dose dependent). 4.DMBA is a po- tent carcinogen as it produced oral epithelial dysplasia in six weeks and oral squamous cell carcinoma in twelve weeks even after stopping DMBA.

\section{References}

1. Johnson NW, Warnakulasuriya $\mathrm{S}$, Gupta PC, et al. Global oral health inequalities in incidence and outcomes for oral cancer: causes and solutions. Adv Dent Res. 2011; 23 (2): 237-34.

2. Fuller C, Camilon R, Nguyen S, Jennings J, Gillespie MB. Adjunctive diagnostic techniques for oral lesions of unknown malignant potential: Systematic review with meta-analysis. Head Neck. 2015; 37 (5): 755-62.

3. Chinn SB, Myers JN. Oral cavity carcinoma: current management, controversies, and future directions. J Clin Oncol. 2015, 33 (29): 2935-41.

4. Branes L, Eveson JW, Reichart P and World DS. WHO classification of tumors: Tumors of the oral cavity and oropharynx. Pathol Genet. 2005; 67:177-179. 
5. El-Mofty S. Early detection of oral cancer. J Oral Maxillofac Surg. 2010; 1: 25-31.

6. Chhaparwal Y, Pai K, , Vineetha R. Chemoprevention of oral cancer. J Ind Acad Oral Med Radiol. 2012; 24 (1): 3944.

7. Mohamed A, Afridi DM, Garani O, Tucci $M$. Thymoquinone inhibits the activation of NF-kappaB in the brain and spinal cord of experimental autoimmune encephalomyelitis. Biomed Sci Instrum. 2005; 41: 388-93.

8. AbuKhader MM. Thymoquinone: $A$ promising antidiabetic agent. Int $\mathrm{J}$ Diabetes Dev Ctries. 2012; 32 (2): 65-8.

9. Kalemci S, Cilaker Micili S, Acar T, et al. Effectiveness of thymoquinone in the treatment of experimental asthma. Clin Ter. 2013; 164 (3): 155-8.

10. Kazemi M. Chemical composition and antioxidant properties of the essential oil of Nigella sativa L. Bangl J Bot. 2015; 44 (1): 111-116.Not found

11. Abukhader MM. Thymoquinone in the clinical treatment of cancer: Fact or fiction? Pharmacogn Rev. 2013; 7 (14): 117-20.

12. Hanahan D, Weinberg RA. Hallmarks of cancer: The next generation cell. Cell. 2011; 144 (5): 646-74.

13. Schneider-Stock R, Fakhoury IH, Zaki AM, El-Baba CO, Gali-Muhtasib HU. Thymoquinone: Fifty years of success in the battle against cancer models. Drug Discov Today. 2014; 19 (1): 18-30.

14. Nishiyama N. Nanomedicine: nanocarriers shape up for long life. Nat Nanotechnol. 2007; 2 (4): 203-4.

15. Wang S, Su R, Nie S, et al. Application of nanotechnology in improving bioavailability and bioactivity of dietderived phytochemicals. J Nutr Biochem. 2014; 25 (4): 363-76.

16. Nagini S. Of humans and hamsters: The hamster buccal pouch carcinogenesis model as a paradigm for oral oncogenesis and chemoprevention. Anticancer Agents Med Chem. 2009; 9(8): 843-52.
17. EL-Dakhakhny M, Hassan MA and Abdel-Aziz G. Effect of thymoquinone and polythymoquinone on chemically-induced oral epithelial dysplasia. (Part I). Intern J Acad Res. 2009; 1 (2): 107117. Not found

18. Abdel-Aziz DMM, Hassan MMA, El-Refai $\mathrm{MH}$ and El-Swify AA. Chemopreventive effect of green tea on 9, 12 dimethylbenz-(a)-anthracene (DMBA)- induced hamster buccal pouch carcinogenesis. Suez Canal Med J. 2009; 12 (1): 77-84.

19. Shklar G. Experimental oral pathology in the Syrian hamster. Prog Exp Tumor Res. 1972; 16:518-38.

20. Chiang CP, Huang WT, Lee JW, Hsu YC. Effective treatment of 7,12dimethylbenz (a) anthracene-induced hamster buccal pouch precancerous lesions by topical photosan-mediated photodynamic therapy. Head Neck. 2012; 34(4):505-12.

21. Yang K, Zhang G, Mei J, Chen D, Wu M. Screening and analysis of pathogenic genes during DMBA-induced buccal mucosa carcinogenesis in golden hamsters. Oncol Rep. 2010; 23(6):1619-24

22. Odeh F, Ismail SI, Abu-Dahab R, Mahmoud IS, Al Bawab A. Thymoquinone in liposomes: A study of loading efficiency and biological activity towards breast cancer. Drug Deliv. 2012; $19(8): 371-7$.

23. Cabral H, Matsumoto $\mathrm{Y}$, Mizuno K, et al. Accumulation of sub-100 nm polymeric micelles in poorly permeable tumours depends on size. Nat Nanotechnol. 2011; 6 (12): 815-23.

24. Wang H, Wang S, Su H, et al. A supramolecular approach for preparation of size-controlled nanoparticles. Angew Chem Int Ed Engl. 2009; 48(24):4344-8.

25. iang W, Kim BY, Rutka JT, Chan WC. Nanoparticle-mediated cellular response is size-dependent. Nat Nanotechnol. 2008; 3 (3):145-50.

26. AL-Jawfi K, Hassan $M$ and El-Gohary A. Effect of Nigella sativa oil on the hamster lymphocytes secondary to 
DMBA-induced carcinogenesis. Suez Canal Univ Med J. 2008; 11(1): 75-80.

27. Nahirney PC, Dow PR, Ovalle WK. Quantitative morphology of mast cells in skeletal muscle of normal and genetically dystrophic mice. Anat Rec. 1997; 247(3): 341-9.

28. Zhou L, Porter JD, Cheng G, et al. Temporal and spatial mRNA expression patterns of TGFbeta1, 2, 3 and TbetaRI, II, III in skeletal muscles of $\mathrm{mdx}$ mice. Neuromuscul Disord. 2006; 16(1): 32-8.

29. Brandan E, Cabello-Verrugio C, Vial C. Novel regulatory mechanisms for the proteoglycans decorin and biglycan during muscle formation and muscular dystrophy. Matrix Biol. 2008; 27(8): 700-8.

30. Zhu J, Li Y, Shen W, et al. Relationships between transforming growth factorbeta1, myostatin, and decorin: Implications for skeletal muscle fibrosis. $J$ Biol Chem. 2007; 282(35): 25852-63.

31. Eveson JW and MacDonald DG. Quantitative histological changes during early experimental carcinogenesis in the hamster cheek pouch. $\mathrm{Br}$ J Dermatol. 1978; 98:639-644.

32. Mourad ME. Immunohistopathological evaluation of the effect of Nigella sativa L. (whole oil) on the DMBAcarcinogenic model in the hamster cheek pouch epithelium. M. Sc. Thesis, Faculty of Dentistry, University of Mansoura, Egypt, 2003.

33. Salley JJ. Experimental carcinogenesis in the cheek pouch of the Syrian hamster. J Den Res. 1954; 33 (2): 253-62.

34. Chiang CP, Huang WT, Lee JW, Hsu YC. Effective treatment of 7,12dimethylbenz (a) anthracene-induced hamster buccal pouch precancerous lesions by topical photosan-mediated photodynamic therapy. Head Neck. 2012; 34(4):505-12.

35. Worthen DR, Ghosheh OA, Crooks PA. The in vitro anti-tumor activity of some crude and purified components of blackseed, Nigella sativa L. Anticancer Res. 1998; 18 (3A): 1527-32.
36. El-Mezayen R, El Gazzar M, Nicolls MR, Marecki JC, Dreskin SC and Nomiyama H. Effect of thymoquinone on cyclooxygenase expression and prostaglandin production in a mouse model of allergic airway inflammation. Immunol Lett. 2006; 106 (1): 72-78.

37. Gali-Muhtasib H, Diab-Assaf M, Boltze $C$, et al. Thymoquinone extracted from black seed triggers apoptotic cell death in human colorectal cancer cells via a p53-dependent mechanism. Int J Oncol. 2004; 25 (4): 857-66.

38. Hussain AR, Ahmed $M$, et al. Thymoquinone suppresses growth and induces apoptosis via generation of reactive oxygen species in primary effusion lymphoma. Free Radic Biol Med. 2011; 50 (8): 978-87.

39. Yi T, Cho SG, Yi Z, et al. Thymoquinone inhibits tumor angiogenesis and tumor growth through suppressing AKT and extracellular signal-regulated kinase signaling pathways. Mol Cancer Ther. 2008; 7 (7): 1789- 96.

40. Kolli-Bouhafs K, Boukhari A, Abusnina $A$, et al. Thymoquinone reduces migration and invasion of human glioblastoma cells associated with FAK, MMP-2 and MMP-9 downregulation. Invest New Drugs. 2012; 30 (6): 2121-31.

41. Munro N. Hematologic complications of critical illness: Anemia, neutropenia, thrombocytopenia, and more. Aacn Adv Critical Care. 2009; 20 (2): 145-54.

42. Miyata M, Furukawa M, Takahashi K, Gonzalez FJ, Yamazoe Y. Mechanism of 7,12-dimcthylbenz(a)anthracene-induced immunotoxicity: Role of metabolic activation at the target organ. Jpn J Pharmacol. 2001; 86 (3): 302-9.

43. Galvan N, Page TJ, Czupiynski CJ, Jefcoate CR. Benzo(a)-pyrene and 7,I2dimethylbenz(a)-anthrecene differentially affect bone marrow cells of the lymphoid and myeloid lineages. Toxicol Appl Pharmacol. 2006; 213 (2): 105-16. 
44. Ali BH, Blunden G. Pharmacological and toxicological properties of Nigella sativa. 2003; 17 (4): 299-305.

45. Ho-Tin-Noé B, Demers $M$, Wagner DD. How platelets safeguard vascular integrity. J Thromb Haemost. 2011; 9 (1):56-65.
46. Buergy D, Wenz F, Groden C, Brockmann MA. Tumor-platelet interaction in solid tumors. Int J Cancer. 2012; 130 (12): 2747-60. 